\title{
Multiple Defects in Muscle Glycogen Synthase Activity Contribute to Reduced Glycogen Synthesis in Non-Insulin Dependent Diabetes Mellitus
}

Anne W. Thorburn, Barry Gumbiner, Fred Bulacan, Ginger Brechtel, and Robert R. Henry

Department of Medicine, University of California, San Diego; and the Metabolism Division,

Veterans Administration Medical Center, San Diego, California 92161

\begin{abstract}
To define the mechanisms of impaired muscle glycogen synthase and reduced glycogen formation in non-insulin dependent diabetes mellitus (NIDDM), glycogen synthase activity was kinetically analyzed during the basal state and three glucose clamp studies (insulin $\cong 300,700$, and $33,400 \mathrm{pmol} /$ liter) in eight matched nonobese NIDDM and eight control subjects. Muscle glycogen content was measured in the basal state and following clamps at insulin levels of 33,400 pmol/liter. NIDDM subjects had glucose uptake matched to controls in each clamp by raising serum glucose to $15-20 \mathrm{mmol} /$ liter.

The insulin concentration required to half-maximally activate glycogen synthase $\left(E D_{50}\right)$ was approximately fourfold greater for NIDDM than control subjects $(1,004 \pm 264$ vs. $257 \pm 110 \mathrm{pmol} / \mathrm{liter}, P<0.02)$ but the maximal insulin effect was similar. Total glycogen synthase activity was reduced $\sim 38 \%$ and glycogen content was $\sim 30 \%$ lower in NIDDM. A positive correlation was present between glycogen content and glycogen synthase activity $(r=0.51, P<0.01)$.

In summary, defects in muscle glycogen synthase activity and reduced glycogen content are present in NIDDM. NIDDM subjects also have less total glycogen synthase activity consistent with reduced functional mass of the enzyme. These findings and the correlation between glycogen synthase activity and glycogen content support the theory that multiple defects in glycogen synthase activity combine to cause reduced glycogen formation in NIDDM. (J. Clin. Invest. 1991. 87:489-495.) Key words: insulin action • glucose disposal • nonoxidative glucose metabolism • enzyme kinetics • glucose-6-phosphate
\end{abstract}

\section{Introduction}

Glycogen synthesis is a major pathway of glucose disposal in skeletal muscle (1). Changes in the activity of glycogen synthase (EC 2.4.1.11), either by allosteric regulators or covalent modification, regulate the synthesis of glycogen. In muscle, glycogen synthase exists mainly in active dephosphorylated forms or less active phosphorylated forms (2). These forms are interconverted by protein kinase and phosphatase reactions with glucose-6-phosphate $(\mathrm{G} 6 \mathrm{P})^{1}$ stimulating the phosphatase reac-

Address reprint requests to Dr. Robert R. Henry, Veterans Administration Medical Center (V-11 1G), 3350 La Jolla Village Drive, San Diego, CA 92161.

Received for publication 27 April 1990 and in revised form 27 September 1990.

1. Abbreviations used in this paper: FFM, fat-free mass; G6P, glucose6-phosphate; NIDDM, non-insulin dependent diabetes mellitus; UDPG, uridine 5'-diphosphate glucose.

The Journal of Clinical Investigation, Inc.

Volume 87, February 1991, 489-495 tion (3-5), while insulin is thought to act by decreasing the kinase (6) as well as increasing the phosphatase reactions (7).

A recent study using ${ }^{13} \mathrm{C}$-nuclear magnetic resonance spectroscopy has shown that muscle glycogen formation is reduced by $57 \%$ at an insulin concentration of 400 pmol/liter in non-insulin dependent diabetes mellitus (NIDDM) (1). This decrease in glycogen synthesis, however, could be the result of impaired glycogen synthase activity, reduced muscle glucose uptake, or a combination of these factors. This study was carried out to address whether defective glycogen synthase activity alone plays a major role in impaired glycogen formation in NIDDM.

Most current evidence indicates that diabetes is associated with reduced glycogen synthase activity. In animals, diabetes induced by streptozotocin, alloxan, or pancreatectomy has been shown to blunt the ability of insulin to promote glucose incorporation into glycogen $(8,9)$ as well as the ability of insulin to lower the sensitivity of the enzyme for $\operatorname{G6P}(10,11)$. A number of recent studies conducted in human subjects have also documented reduced glycogen synthase activity in insulinresistant states including NIDDM $(7,12-17)$. However, the nature and extent of the glycogen synthase defect in muscle and its role in reduced glycogen formation in NIDDM has not yet been clearly elucidated. Bogardus and co-workers have reported correlations between muscle glycogen synthase activity and insulin-mediated glucose uptake in subjects with varying insulin sensitivity, implying that glycogen synthase activity is impaired in NIDDM, although the defects were not quantitated at rates of tissue glucose uptake comparable to normal subjects $(7,12,13)$. In subjects with frank NIDDM, Wright et al. calculated muscle glycogen synthase activity to be $25 \%$ less than control subjects after ingesting a meal (14). Although this study assessed glycogen synthase activity in response to a physiologic stimulus, the fact that it was conducted under nonsteady-state conditions with varying glucose and insulin concentrations did not allow the role of these parameters in the glycogen synthase defect to be ascertained. In a recent study that normalized glucose uptake in NIDDM using hyperglycemia during hyperinsulinemic ( $\sim 300$ pmol/liter) glucose clamps, reduced muscle glycogen synthase activity (as measured by fractional velocity) was documented in NIDDM compared with nondiabetic subjects under steady-state conditions (17). Increasing the insulin level fourfold overcame this defect. Therefore, although previous studies have shown NIDDM to be associated with impaired muscle glycogen synthase activity and reduced glycogen formation, little information is currently available that characterizes the extent of this enzymatic defect over a range of insulin concentrations or defines the mechanism for this defect and its potential role in decreased glycogen formation in NIDDM.

To address these questions in this study, the kinetics of both insulin and G6P activation of glycogen synthase activity, as well as total glycogen synthase activity and glycogen content in muscle were compared in subjects with non-insulin dependent 
diabetes mellitus and nondiabetic (control) subjects over a range of insulin concentrations from basal to $33,400 \mathrm{pmol} /$ liter. To examine any defects at each insulin level independent of reduced glucose uptake, studies were performed at equivalent rates of glucose uptake in the NIDDM and control subjects.

\section{Methods}

Subjects. Eight male subjects with NIDDM and eight male nondiabetic (control) subjects with normal glucose tolerance (18) were studied. Table I lists the clinical characteristics of the subjects. Age, weight, fat-free mass (FFM), and body mass index were not significantly different in the NIDDM and control subjects. The NIDDM subjects did not have significant diabetic complications or hypertension. Five subjects were on sulfonylurea therapy, one was on insulin, one was on diet therapy only, and one had been recently diagnosed and not yet treated. All treatment for diabetes was withdrawn at least two weeks before the studies. No subject was taking any other medication known to affect carbohydrate metabolism. Duration of overt diabetes was $10 \pm 3$ yr (mean \pm SEM). Fasting glycosylated hemoglobin in the NIDDM subjects was $9.4 \pm 1: 2 \%$. The normal reference range for this assay is 4.1 $8.1 \%$. The control subjects were screened to ensure they were healthy and had no family history of diabetes. Some of the data derived from these studies has been reported previously $(17,20,21)$. Written informed consent was obtained from each subject and the experimental protocol approved by the Committee on Human Investigation of the University of California, San Diego.

Study protocol. Subjects were admitted to the Special Diagnostic and Treatment Unit of the Veterans Administration Medical Center in San Diego and consumed a weight-maintenance standardized solid diet containing $55 \%$ of calories as carbohydrate, $30 \%$ as fat, and $15 \%$ as protein during hospitalization.

Three studies were carried out in both the NIDDM and control subjects. Each study was performed after a 12-14-h overnight fast and lasted $\sim 7.5 \mathrm{~h}:$ a 2.5 -h basal period followed by a 5 -h hyperinsulinemic glucose clamp. Basal serum glucose and insulin concentrations were higher in the NIDDM than in control subjects $(P<0.05$, Table II). The serum glucose and insulin levels used during the clamps are also listed in Table II. Clamps A, B, and C were conducted at insulin infusion rates of 150,300 , and $4,000 \mathrm{pmol} / \mathrm{m}^{2}$ per min, respectively (equivalent to $\sim 20,40$, and $600 \mathrm{mU} / \mathrm{m}^{2}$ per $\mathrm{min}$ ). Clamps $\mathrm{A}$ and $\mathrm{B}$ were carried out at euglycemia $(5 \mathrm{mmol} /$ liter $)$ in the control subjects and at hyperglycemia (15-20 mmol/liter) in the NIDDM subjects to match glucose uptake rates in the NIDDM group to those of the control group. Clamp $C$ was carried out first in the NIDDM subjects at pharmacologic insulin concentrations and hyperglycemia (15-20 mmol/liter) to maximally stimulate glucose uptake. In the control subjects, clamp $\mathrm{C}$ was then conducted at the same insulin level as the NIDDM group and glucose uptake rate was matched to the NIDDM subjects by varying the level of hyperglycemia.

Details of the study procedures have been described previously (17, 22). Briefly, $3-\left[{ }^{3} \mathrm{H}\right]$ glucose was infused as a $45-\mu \mathrm{Ci}$ bolus dose followed

Table I. Clinical Characteristics of the Subjects*

\begin{tabular}{lcc}
\hline & NIDDM subjects & Control subjects \\
\hline Age $(y r)$ & $59 \pm 3$ & $58 \pm 5$ \\
Weight $(\mathrm{kg})$ & $78.8 \pm 5.0$ & $74.2 \pm 4.0$ \\
Fat-free mass $(\mathrm{kg})^{\ddagger}$ & $60.5 \pm 3.8$ & $56.4 \pm 2.7$ \\
Body mass index $\left(\mathrm{kg} / \mathrm{m}^{2}\right)$ & $25.4 \pm 1.1$ & $24.4 \pm 1.0$
\end{tabular}

* Data expressed as mean \pm SEM.

₹ Determined by underwater weighing with correlation for residual lung volume (19).
Table II. Serum Glucose and Insulin Concentrations and Rates of Glucose Uptake in the Control and NIDDM Subjects

\begin{tabular}{lccc}
\hline & Serum glucose & Serum insulin & Glucose uptake \\
\hline & $m m o l / l i t e r$ & $p m o l / l i t e r$ & $m g / k g$ FFM per min \\
Basal & & & \\
NIDDM & $9.9 \pm 1.1^{*}$ & $64 \pm 14^{\ddagger}$ & $3.75 \pm 0.23^{\S}$ \\
Control & $4.9 \pm 0.1$ & $36 \pm 7$ & $2.49 \pm 0.10$ \\
Clamp A & & & \\
NIDDM & $20.7 \pm 1.6^{\S}$ & $258 \pm 57$ & $8.62 \pm 0.49$ \\
Control & $5.1 \pm 0.1$ & $287 \pm 43$ & $8.25 \pm 0.48$ \\
Clamp B & & & \\
NIDDM & $17.6 \pm 2.2^{8}$ & $646 \pm 65$ & $11.24 \pm 0.34$ \\
Control & $5.1 \pm 0.1$ & $740 \pm 72$ & $11.76 \pm 0.75$ \\
Clamp C & & & \\
NIDDM & $18.4 \pm 1.2$ & $33136 \pm 2369$ & $25.58 \pm 1.66$ \\
Control & $15.3 \pm 2.2$ & $34694 \pm 5873$ & $27.21 \pm 1.28$ \\
\hline
\end{tabular}

${ }^{\ddagger} P<0.05,{ }^{*} P<0.01$, and ${ }^{\S} P<0.001$ for NIDDM vs. control values.

by a continuous infusion of $0.60 \mu \mathrm{Ci} / \mathrm{min}$ during the entire study to isotopically determine rates of hepatic glucose output and glucose appearance $(23,24)$. Glucose uptake rates (in milligrams per kilogram FFM per minute) were calculated during the basal state in each subject from the rate of glucose appearance corrected for changes in glucose pool size and urinary glucose loss, if present. Glucose uptake rates were calculated during each clamp study in each subject from the glucose infusion rate corrected for changes in glucose pool size, urinary glucose loss, and residual HGO. The clamp was started with an intravenous infusion of insulin (crystalline human insulin [Humulin R], kindly supplied by Eli Lilly \& Co., Indianapolis, IN) given as a bolus followed by a continuous rate of insulin infusion. Serum glucose was clamped at the desired concentration by varying the infusion of $20 \%$ glucose. Somatostatin $(0.08 \mathrm{pmol} / \mathrm{kg}$ per min, cyclic form; Bachem Inc., Torrance, $\mathrm{CA}$ ) was infused in all studies to suppress endogenous insulin secretion. $\mathrm{KCl}$ and $\mathrm{K}_{2} \mathrm{PO}_{4}$ were infused at a rate of $0.16 \mathrm{mmol} /$ liter to maintain serum potassium levels. During the last $30 \mathrm{~min}$ of the basal and clamp periods, steady-state measurements were made of rates of glucose uptake, serum glucose, and serum insulin. Glycogen synthase activity in samples of vastus lateralis muscle was determined four times in each subject; at the end of one of the basal periods and at the completion of each of the three clamp studies. Glycogen content was also measured in muscle collected from basal and clamp $\mathrm{C}$ studies to determine whether glycogen synthase correlated with the glycogen content in muscle from the NIDDM and control subjects in these studies. Glycogen was not measured in clamps $A$ and $B$ since the expected increase in glycogen would likely be within the coefficient of variation of the measurement for muscle glycogen from biopsy samples (25).

Glycogen synthase determination. Percutaneous muscle biopsies were obtained from the vastus lateralis muscle with a 5-mm diameter side-cutting needle using a modification of the procedure described by Bergstrom (26). Muscle samples were blotted to remove any blood, immediately placed into liquid nitrogen, and stored until assayed. Glycogen synthase (EC 2.4.1.11) was measured using modifications of the methods of Nuttall et al. (27) and Thomas et al. (28). This modified method has been described in detail previously $(14,17,29)$. Glycogen synthase activity was assayed in a homogenate of $50 \mathrm{mg}$ of muscle by measuring the incorporation of $\left[{ }^{14} \mathrm{C}\right]$ glucose from uridine 5 -diphosphate glucose (UDPG) into glycogen. Protein was also assayed in the extract (30) and units of glycogen synthase activity expressed as nanomoles of $\left[{ }^{14} \mathrm{C}\right] U D P G$ incorporated into glycogen per minute per milligram of protein. Glycogen synthase activity was assayed over a range of glucose-6-phosphate concentrations $(0,0.1,0.3,0.5,1.0,5.0$, and 10.0 $\mathrm{mmol} /$ liter G6P) at physiologic levels of substrate $(0.3 \mathrm{mmol} / \mathrm{liter}$ 
UDPG). Results are expressed as the fractional velocity of glycogen synthase, i.e., the activity assayed at $0.1 \mathrm{mmol} / \mathrm{liter} \mathrm{G} 6 \mathrm{P}$ divided by the activity at $10 \mathrm{mmol} /$ liter G6P. In addition, glycogen synthase activity was measured in each biopsy specimen at saturating concentrations of UDPG ( $5 \mathrm{mmol} /$ liter $)$ and G6P ( $10 \mathrm{mmol} /$ liter $)$ to assess the total activity of the enzyme.

Muscle glycogen concentration. The glycogen content of muscle was determined using a modification of the method used by Keppler and Decker (31). Before analysis, muscle samples were freeze-dried and powdered to remove connective tissue and any dilution factor due to the presence of blood. A portion of dried muscle $(8 \mathrm{mg})$ was homogenized with 80 parts by weight of $0.6 \mathrm{M}$ perchloric acid, and $40 \mu \mathrm{l}$ of the muscle homogenate was added to $20 \mu 1 \mathrm{KHCO}_{3}$ solution ( $1 \mathrm{~mol} / \mathrm{liter}$ ), $385 \mu$ l acetate buffer ( $\mathrm{pH} 4.8$ ) plus $14.8 \mu$ l glucoamylase solution ( 270 $\mathrm{U} / \mathrm{ml}$; Sigma Chemical Co., St. Louis, MO) and incubated at $40^{\circ} \mathrm{C}$ for $2 \mathrm{~h}$ while shaking. After incubation, another $200 \mu \mathrm{l}$ of perchloric acid was added before centrifugation and removal of the supernatant. The supernatant was neutralized to $\mathrm{pH} 7$ with solid $\mathrm{KHCO}_{3}$ and recentrifuged. The concentration of free glucose in the muscle homogenate was also measured after neutralization. Total and free glucose were measured in $50 \mu$ l of the samples after adding ATP/NADP/G6P dehydrogenase buffer and $5 \mu \mathrm{l}$ of a hexokinase suspension $(433 \mathrm{U} / \mathrm{ml}$, Sigma). Results were expressed in millimoles glycosyl units per kilogram dry muscle.

Analytical methods. Serum glucose was determined after centrifugation (Eppendorf microcentrifuge; Brinkmann Instruments, Inc., Westbury, NY) by the glucose oxidase method on a Model 23A instrument (Yellow Springs Instrument Co., Yellow Springs, $\mathrm{OH}$ ). Blood for serum insulin was collected in untreated tubes and allowed to clot at room temperature before the supernatant was removed and frozen at $-20^{\circ} \mathrm{C}$. Insulin was measured by a specific double-antibody radioimmunoassay (32). Blood for analysis of plasma glucose specific activity was collected in tubes containing potassium oxalate plus sodium fluoride. Total glycosylated hemoglobin was determined on freshly drawn whole blood using the Glyc-Afin GHb test kit (Isolab, Inc., Akron, $\mathrm{OH}$ ).

Statistical analysis. Kinetic analysis of glycogen synthase activity (expressed as fractional velocity) in response to insulin was determined from individual dose-response curves. The sensitivity of glycogen synthase to insulin was assessed from the insulin concentration at which glycogen synthase activity was half-maximal $\left(\mathrm{ED}_{50}\right) . E_{\max }$ was defined as the maximal effect of insulin on glycogen synthase activity.

To determine the sensitivity of glycogen synthase to G6P, kinetic analysis of the sigmoidal G6P dose-response curve for glycogen synthase was also performed. The concentration of G6P producing halfmaximal activation of the enzyme $\left(A_{0.5}\right)$ was determined by fitting the data to an Eadie-Hofstee equation: $V_{\mathrm{i}}=\left[-A_{0.5} \times V_{\mathrm{i}} /\left[S_{\mathrm{i}}\right]\right]+V_{\max }{ }^{\text {app }}$ where $V_{\mathrm{i}}$ is glycogen synthase activity, $S_{\mathrm{i}}$ is G6P concentration, and $V_{\max }{ }^{a p p}$ is the activity of the enzyme at a saturating G6P concentration.

Data calculations and statistical analysis were performed using the StatView II program (Abacus Concepts, Inc., Berkeley, CA). All data are expressed as mean \pm SEM. Statistical significance was tested using analysis of variance followed by the Student's two-tailed paired $t$ test.

\section{Results}

\section{Rates of glucose uptake (Table II)}

In the basal state, rates of glucose uptake were $51 \%$ higher in the NIDDM than control subjects (Table II, $P<0.001$ ). When insulin levels were raised to $\sim 300 \mathrm{pmol} / \mathrm{liter}$ in clamp A performed at euglycemia in the control subjects, the glucose uptake rate increased threefold from basal to $8.25 \mathrm{mg} / \mathrm{kg}$ FFM per min. A similar glucose uptake rate was achieved in clamp $A$ in the NIDDM subjects at the same insulin level by increasing the serum glucose concentration to $\sim 20 \mathrm{mmol} / \mathrm{liter}(P<0.05$ vs. controls). In clamp B, glucose uptake was stimulated further to $\sim 11.5 \mathrm{mg} / \mathrm{kg}$ FFM per min in both subject groups by increasing insulin levels to $\sim 700 \mathrm{pmol} / \mathrm{liter}$, and increasing serum glucose to $\sim 18 \mathrm{mmol} /$ liter in the NIDDM subjects while maintaining serum glucose at euglycemia in the control subjects. Maximal rates of glucose uptake were achieved in clamp $C$ in the NIDDM subjects by raising insulin levels to $\sim 33,000$ $\mathrm{pmol} /$ liter and increasing serum glucose to $\sim 18 \mathrm{mmol} /$ liter. Glucose uptake in clamp $C$ in the control group was matched to the NIDDM subjects using a similar insulin level while increasing serum glucose to $\sim 15 \mathrm{mmol} /$ liter.

\section{Insulin dose-response curves for glycogen synthase activation (Figs. 1 and 2)}

Effect of insulin on glycogen synthase activity at physiologic levels of substrate (UDPG $=0.3 \mathbf{~ m m o l} /$ liter) (Fig. 1). Fig. 1 illustrates the insulin dose-response activation of glycogen synthase activation expressed as fractional velocity in the NIDDM and control subjects. In both the NIDDM and control groups, insulin significantly stimulated glycogen synthase activity. However, activation of glycogen synthase by insulin was significantly reduced in the NIDDM compared with control subjects in the basal state and at matched physiologic stimulated rates of glucose uptake (clamps A and B). Glycogen synthase was reduced by $52 \%$ at basal $(P<0.01), 46 \%$ during clamp A ( $P$ $<0.02)$ and $35 \%$ during clamp B $(P<0.04)$. Glycogen synthase activity was not significantly different, however, during clamp C.

Kinetic analysis of individual dose-response curves revealed a significantly higher insulin concentration for halfmaximal stimulation of glycogen synthase activity $\left(E D_{50}\right)$ in NIDDM compared with control subjects $(1,004 \pm 264$ vs. $257 \pm 110 \mathrm{pmol} / \mathrm{liter}$, respectively, $P<0.02)$. However, the maximal effect of insulin on glycogen synthase activity $\left(E_{\max }\right)$ was similar in the NIDDM and control subjects $(0.230 \pm 0.021$ vs. $0.206 \pm 0.023$, respectively, $P=\mathrm{NS}$ ).

Effect of insulin on total glycogen synthase activity at maximal concentrations of substrate (UDPG $=5 \mathrm{mmol} / \mathrm{liter}$ ) and

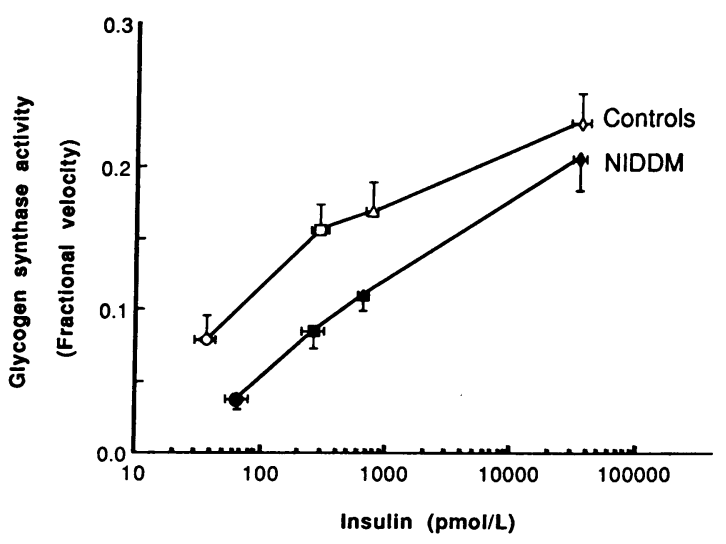

Figure 1. Effect of insulin on muscle glycogen synthase activity (expressed as fractional velocity $=$ the glycogen synthase activity at $0.1 \mathrm{mmol} / \mathrm{liter} \mathrm{G} 6 \mathrm{P}$ divided by the activity at $10 \mathrm{mmol} / \mathrm{liter} \mathrm{G} 6 \mathrm{P}$ at subsaturating UDPG of $0.3 \mathrm{mmol} / \mathrm{liter}$ ) in NIDDM and control subjects during basal conditions (circles) and three glucose clamps (clamp A, squares, $300 \mathrm{pmol} / \mathrm{liter}$; clamp B, triangles, $700 \mathrm{pmol} / \mathrm{liter}$; clamp C, diamonds, 33,400 pmol/liter). Significant differences were found between subject groups in the basal state $(P<0.01)$, and during clamp A $(P<0.02)$ and clamp B $(P<0.04)$ but not clamp C. 


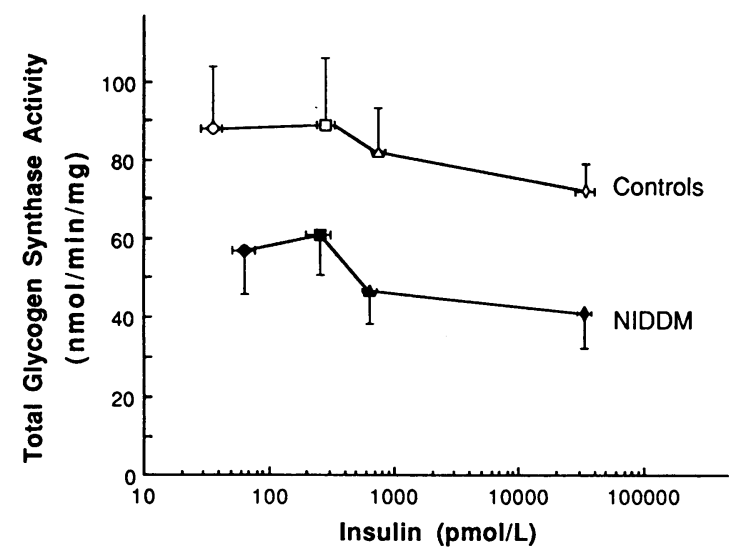

Figure 2. Effect of insulin on total glycogen synthase activity (in nanomoles per minute per milligram protein) at saturating levels of UDPG ( $5 \mathrm{mmol} /$ liter) and G6P ( $10 \mathrm{mmol} / \mathrm{liter})$ in NIDDM and control subjects under basal conditions (circles) and three glucose clamps (clamp A, squares, $300 \mathrm{pmol} /$ liter; clamp B, triangles, 700 pmol/liter; clamp C, diamonds, 33,400 pmol/liter). Significant differences between subject groups were found in the basal state $(P$ $<0.05)$ and during clamp $C(P<0.03)$

activator (G6P $=10 \mathrm{mmol} /$ liter) (Fig. 2). Fig. 2 illustrates the insulin dose-response curves for total glycogen synthase activity (expressed in nanomoles per minute per milligram protein) in the NIDDM and control subjects at maximal concentrations of both substrate (UDPG, $5 \mathrm{mmol} / \mathrm{liter}$ ) and allosteric activator (G6P, $10 \mathrm{mmol} / \mathrm{liter}$ ). Within both the NIDDM and control groups, insulin did not significantly increase total glycogen synthase activity. Mean total glycogen synthase activity was $\sim 38 \%$ lower under all conditions (basal and stimulated) for the NIDDM compared with control subjects.

Glucose 6-phosphate dose-response curves for glycogen synthase activation at physiologic levels of substrate (UDPG $=0.3 \mathrm{mmol} /$ liter) (Figs. 3 and 4)

The G6P dose-response curves for glycogen synthase activity (in nanomoles per minute per milligram protein) for the NIDDM and control subjects are illustrated in Fig. 3. As the insulin concentration increased there was a leftward shift in the dose-response curves. The shift was less pronounced, however, for NIDDM than control subjects. To analyze these sigmoidal G6P dose-response curves (Fig. 3), kinetic analysis was performed using the Eadie-Hofstee equation (see Methods) to determine the half-maximal activation of glycogen synthase by $\operatorname{G6P}\left(A_{0.5}\right)$. Fig. 4 illustrates the insulin dose-response curves for the $A_{0.5}$ for G6P in the NIDDM and control subjects. Insulin decreased the $A_{0.5}$ for G6P in both the NIDDM and control groups. However, $A_{0.5}$ values for basal and clamp A were significantly higher for the NIDDM than control subjects $(4.49 \pm 0.97$ vs. $2.86 \pm 1.09$ for basal, and $1.57 \pm 0.23$ vs. $0.64 \pm 0.08 \mathrm{mmol} /$ liter for clamp A, both $P<0.01$ ). As insulin levels increased above $\sim 700 \mathrm{pmol} /$ liter in clamps $\mathrm{B}$ and $\mathrm{C}$, no significant differences were observed in $A_{0.5}$ between the NIDDM and control subjects.

\section{Muscle glycogen content (Table III)}

The muscle glycogen content in the basal state and during clamp C in NIDDM and control subjects is shown in Table III. In the NIDDM subjects, glycogen was $33 \%$ and $29 \%$ lower
A CONTROLS

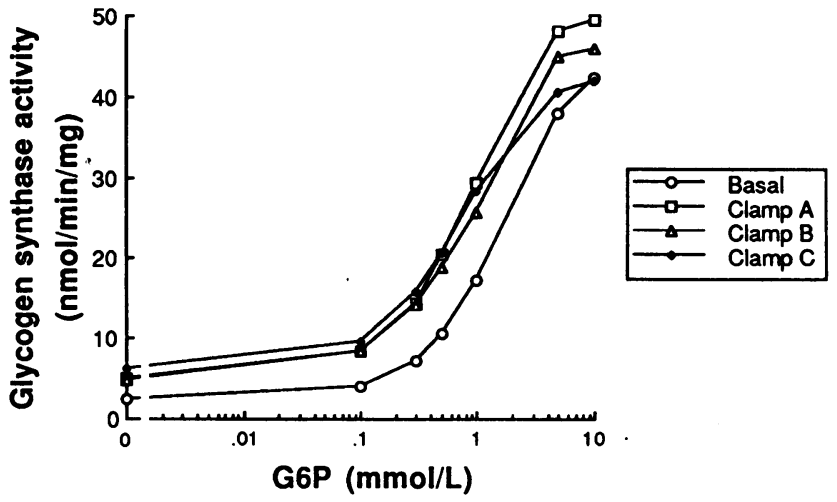

B NIDDM

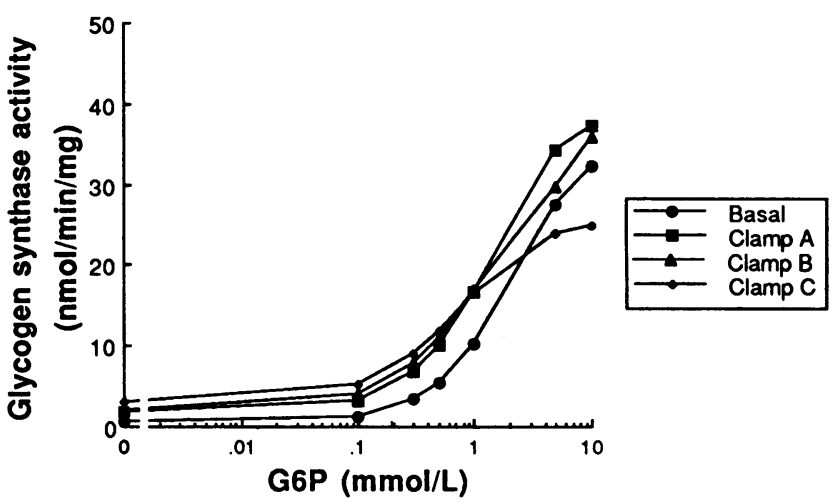

Figure 3. Effect of G6P on glycogen synthase activity (in nanomoles per minute per milligram protein) at subsaturating concentrations of UDPG $(0.3 \mathrm{mmol} / \mathrm{liter})$ in NIDDM and control subjects under basal conditions and three glucose clamps (clamp A, 300 pmol/liter; clamp B, 700 pmol/liter; clamp C, 33,400 pmol/liter).

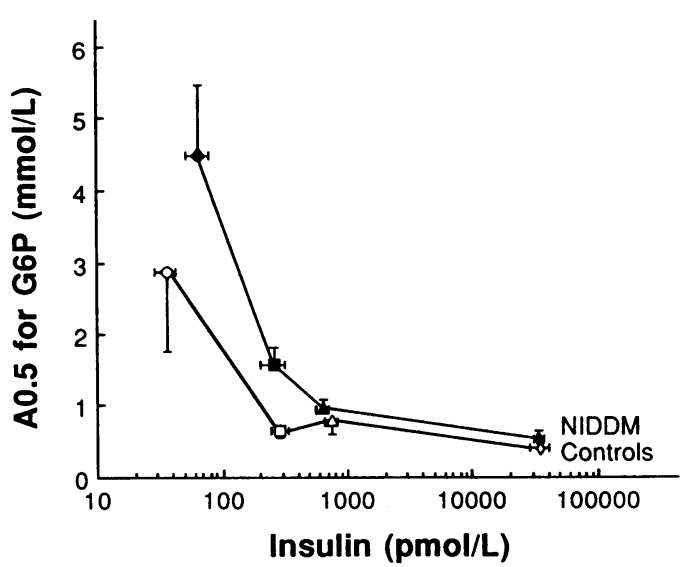

Figure 4. Effect of insulin on the half-maximal activation of glycogen synthase by G6P $\left(A_{0.5}\right)$ was determined using the Eadie-Hofstee equation and data points from Fig. 3. Results from NIDDM and control subjects are shown under basal conditions (circles) and three glucose clamps (clamp A, squares, 300 pmol/liter; clamp B, triangles, $700 \mathrm{pmol} /$ liter; clamp C, diamonds, 33,400 pmol/liter). Significant differences were found between NIDDM and control subjects under basal conditions and during clamp A (both $P<0.01$ ). 
Table III. Muscle Glycogen Concentration (Millimoles Glycosyl Units per Kilogram Dry Muscle) in the NIDDM and Control Subjects under Basal Conditions and Clamp C

\begin{tabular}{lcc}
\hline & NIDDM subjects & Control subjects \\
\hline Basal & $238.3 \pm 20.1^{*}$ & $357.3 \pm 42.6$ \\
Clamp C & $397.6 \pm 42.0^{\ddagger}$ & $561.5 \pm 82.6^{\ddagger}$
\end{tabular}

* Significantly different from corresponding study in controls.

${ }^{\ddagger}$ Significantly different from corresponding basal value.

under basal and clamp C conditions, respectively, compared with control subjects, although this reached significance only under basal conditions $(P<0.02)$. Glycogen increased significantly by $67 \%(P<0.005)$ and $57 \%(P<0.05)$ as insulin levels increased from basal to clamp $C$ for NIDDM and control subjects, respectively. These increments were not significantly different $(159.3 \pm 37.0$ vs. $204.2 \pm 84.1 \mathrm{mmol}$ glycosyl units $/ \mathrm{kg}$ dry muscle in the NIDDM and control subjects, respectively, $P$ $=$ NS). As shown in Fig. 5, a significant correlation was found between glycogen content and glycogen synthase activity when individual subjects' data for the basal and clamp $\mathrm{C}$ studies were plotted $(r=0.51, P<0.01)$.

\section{Discussion}

This study has demonstrated that multiple defects in muscle glycogen synthase activity are present in NIDDM and associated with reduced muscle glycogen formation. Although impaired muscle glycogen synthase activity in response to insulin has been well documented in a number of insulin-resistant states $(7,12-17)$, little is known about the nature or extent of these defects. In a previous study carried out during steadystate glucose clamp conditions and insulin levels of $300 \mathrm{pmol} /$ liter, we documented that muscle glycogen synthase activity (expressed as fractional velocity) was reduced by $40 \%$ in NIDDM but could be normalized by increasing insulin levels fourfold (17).

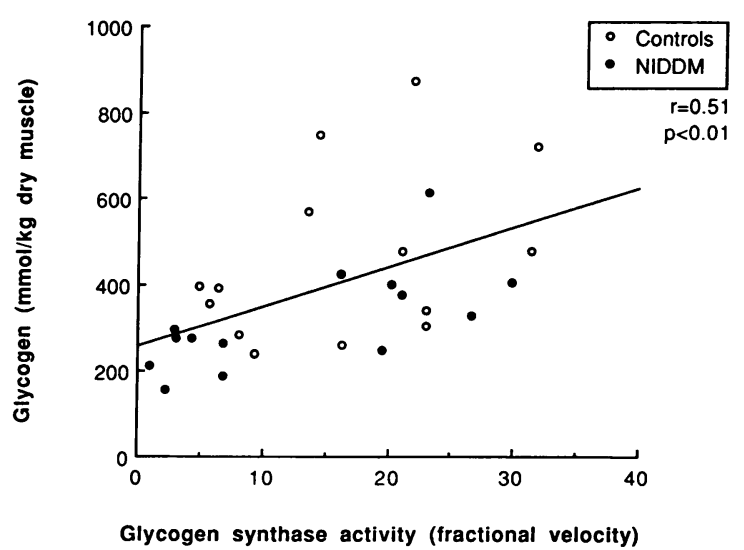

Figure 5. Relationship between muscle glycogen synthase activity (expressed as fractional velocity) and muscle glycogen content (in millimoles glycosyl units per kilogram dry muscle) in the basal state and during clamp $\mathrm{C}$ for seven NIDDM and seven control subjects $(r=28, y=252+9.2 \mathrm{x}, r=0.51, P<0.01)$.
The results of this study led us to examine this defect in greater depth and we have now shown that the fractional velocity of glycogen synthase is reduced by $35-52 \%$ at insulin levels ranging from basal to $\sim 700 \mathrm{pmol} / \mathrm{liter}$. As insulin levels increased, the magnitude of the impairment progressively decreased and at pharmacologic insulin levels of $\sim 33,400 \mathrm{pmol} /$ liter the defect normalized. Kinetic analysis of the insulin doseresponse curves showed that the half-maximal activation constant for insulin was approximately fourfold higher for NIDDM than control subjects, but with no difference in the maximal effect of insulin on glycogen synthase. One possible explanation for the normalization of maximal glycogen synthase activity in NIDDM may be stimulation of enzyme activity by G6P secondary to glucose transport, originally proposed by Lawrence and Larner (33). Therefore, reduced sensitivity of glycogen synthase to physiologic insulin concentrations exists in NIDDM that is overcome when insulin is raised to pharmacologic levels.

In agreement with previous reports $(25,34)$, at each insulin concentration glycogen synthase was activated in the control subjects without changing the total glycogen synthase activity (i.e., the true maximal activity at saturating concentrations of G6P and UDPG). Similarly, increasing insulin levels from basal to clamp $C$ did not significantly change total glycogen synthase activity in the NIDDM subjects. Although total activity was less in the NIDDM subjects than in controls over the range of insulin concentrations studied, it was significantly less only in the basal state and during clamp C. Alterations in the turnover rate of glycogen synthase, such as a decrease in the rate of synthesis, increase in the rate of degradation, or some combination of the two could be responsible for reduced total enzyme activity in NIDDM. Alternatively, NIDDM and control subjects may possess identical amounts of glycogen synthase protein but the enzyme simply has less activity in NIDDM. Whatever the cause, our data strongly suggest that NIDDM subjects have a reduced functional mass of the enzyme, which is not overcome by acutely increasing the serum insulin concentration.

Insulin acts as a major regulator of glycogen synthase in muscle by dephosphorylating the enzyme and reducing the $A_{0.5}$ for G6P. G6P is not only an allosteric effector but also a messenger molecule that can mediate hormone action by stimulating the phosphatase reaction $(4,5)$. In muscle from diabetic rabbits, the half-maximal G6P activation constant for glycogen synthase has been shown to increase by two to threefold compared with nondiabetic animals (11). Our study has now similarly demonstrated that reduced sensitivity of muscle glycogen synthase to allosteric activation by G6P exists in NIDDM. This is an expected finding since the elevated $A_{0.5}$ of glycogen synthase for G6P is likely the result of the increased phosphorylation state of the enzyme, shown by Roach and Larner to be associated with reduced fractional glycogen synthase activity (35). The reduced sensitivity to G6P was overcome at insulin concentrations above $700 \mathrm{pmol} /$ liter since insulin presumably dephosphorylates glycogen synthase to such an extent that the enzyme no longer requires G6P for complete activation.

This study not only examined the extent of defects in glycogen synthase activation by insulin in NIDDM, but also demonstrated that defects in glycogen synthase activity contribute to reduced glycogen content in NIDDM. This study now confirms that glycogen content is reduced in NIDDM, and that glycogen synthase activity remains impaired at physiologic in- 
sulin concentrations even when rates of glucose uptake are normalized. Furthermore, a close correlation between glycogen synthase activity and glycogen content has been clearly demonstrated. Thus, these findings taken together are consistent with the notion that changes in glycogen synthase activity contribute significantly to decreased glycogen content in NIDDM.

When a defect in insulin's ability to activate glycogen synthase has been reported previously, it has usually been accompanied by a corresponding reduced rate of glucose uptake into insulin-sensitive tissues (e.g., 7, 12-16). This association has lead to the suggestion that a causal relationship exists between insulin-stimulation of glycogen synthase and glucose uptake ( 7 , $13,14)$. However, the fact that we found reduced glycogen synthase activity in NIDDM subjects when rates of glucose uptake were normalized indicates that the effect of insulin on muscle glycogen synthase is clearly separable from its effect on glucose transport $(2,17,25,36,37)$ and confirms that reduced glycogen synthase activity in NIDDM is not solely a consequence of reduced glucose uptake. Furthermore, this study provides evidence that activation of glycogen synthase and glucose transport by insulin may occur through different mechanisms.

At present we can only speculate as to the cause of the reduced sensitivity of glycogen synthase to covalent modification and allosteric activation by insulin and G6P in NIDDM. The most likely explanation is that glycogen synthase in muscle from NIDDM subjects is more phosphorylated, and hence inactivated, due to an impairment in the complex pattern of hormonally regulated multisite phosphorylation which controls the activity of glycogen synthase. The recent demonstration by Kida and co-workers that glycogen synthase phosphatase is reduced in insulin-resistant subjects supports this concept (7). Although the etiology of impaired glycogen synthase activity in NIDDM remains to be determined, it has recently been demonstrated that this defect can be reversed, at least partially, in NIDDM subjects by eight weeks of sulfonylurea therapy (38).

In summary, multiple defects in glycogen synthase activity and reduced glycogen content exist in muscle from nonobese NIDDM subjects over a range of physiologic insulin concentrations and similar rates of glucose uptake. NIDDM is associated with a defect in the sensitivity of muscle glycogen synthase to insulin that becomes progressively less as insulin concentrations increase. Increasing the insulin concentration does not, however, overcome the defect in total enzyme activity (i.e., functional enzyme mass). These defects in glycogen synthase activity and the correlation between glycogen synthase activity and glycogen content support the contention that multiple defects in glycogen synthase activity contribute to reduced glycogen deposition in NIDDM.

\section{Acknowledgments}

We gratefully acknowledge the helpful advice received from Dr. Harvey Kaslow, University of Southern California, Los Angeles, and Dr. Ted Ciaraldi, Veterans Administration Medical Center, San Diego, and the assistance of Penny Wallace, Therese Flynn, Michelle Goldberg, Cleon Tate, the research volunteers, and the nursing staff of the Division of Endocrinology and Metabolism, VA Medical Center, San Diego.

This study was supported in part by the American Diabetes Association (ADA), the Medical Research Service of the Veterans Administra- tion Medical Center, grant DK-38949 from the National Institute of Arthritis, Diabetes, and Digestive and Kidney Diseases, and grant PHS RR-00827 from the General Clinical Research Branch, Division of Research Resources, National Institutes of Health. Barry Gumbiner is the recipient of an ADA California Affiliate Fellowship Grant. Anne Thorburn is a Neil Hamilton Fairley Fellow funded by the National Health and Medical Research Council of Australia.

\section{References}

1. Shulman, G. I., D. L. Rothman, T. Jue, P. Stein, R. A. DeFronzo, and R. G. Shulman. 1990. Quantitation of muscle glycogen synthesis in normal subjects and subjects with non-insulin-dependent diabetes by ${ }^{13} \mathrm{C}$ nuclear magnetic resonance spectroscopy. N. Engl. J. Med. 322:223-228.

2. Danforth, W. H. 1965. Glycogen synthetase activity in skeletal muscle. Interconversion of two forms and control of glycogen synthesis. J. Biol. Chem. 240:588-593.

3. Okubo, M., C. Bogardus, S. Lillioja, and D. M. Mott. 1988. Glucose-6phosphate stimulation of human muscle glycogen synthase phosphatase. Metab. Clin. Exp. 37:1171-1176.

4. Gilboe, D. P., and F. Q. Nuttall. 1972. The role of ATP and glucose-6-phosphate in the regulation of glycogen synthetase D phosphatase. Biochem. Biophys. Res. Commun. 48:898-906.

5. Oron, Y., and J. Larner. 1980. Insulin action in intact mouse diaphragm I. Activation of glycogen synthase through stimulation of sugar transport and phosphorylation. Mol. Cell. Biochem. 32:153-160.

6. Okubo, M., C. Bogardus, S. Lillioja, and D. M. Mott. 1989. Adenosine 3',5'-monophosphate-dependent protein kinase activity deceases in human muscle after insulin infusion. J. Clin. Endocrinol. Metab. 69:798-803.

7. Kida, Y., A. Esposito-Del Puente, C. Bogardus, and D. M. Mott. 1990. Insulin resistance is associated with reduced fasting and insulin-stimulated glycogen synthase phosphatase activity in human skeletal muscle. J. Clin. Invest. 85:476-481.

8. Kruszynska, Y. T., and P. D. Home. 1988. Liver and muscle insulin sensitivity, glycogen concentration and glycogen synthase activity in a rat model of non-insulin dependent diabetes. Diabetologia. 31:304-309.

9. Rossetti, L., and M. R. Laughlin. 1989. Correction of chronic hyperglycemia with vanadate, but not with phlorizin, normalizes in vivo glycogen repletion and in vitro glycogen synthase activity in diabetic skeletal muscle. J. Clin. Invest. 84:892-899.

10. Kaslow, H. R., and R. D. Eichner. 1984. Fasting and diabetes alter adipose tissue glycogen synthase. Am. J. Physiol. 247:E581-E584.

11. Sheorain, V. S., B. S. Khatra, and T. R. Soderling. 1982. Hormonal regulation of glycogen synthase phosphorylation in rabbit skeletal muscle. J. Biol. Chem. 257:3462-3470.

12. Freymond, D., C. Bogardus, M. Okubo, K. Stone, and D. Mott. 1988. Impaired insulin-stimulated muscle glycogen synthase activation in vivo in man is related to low fasting glycogen synthase phosphatase activity. J. Clin. Invest. 82:1503-1509.

13. Bogardus, C., S. Lillioja, K. Stone, and D. Mott. 1984. Correlation between muscle glycogen synthase activity and in vivo insulin action in man. $J$. Clin. Invest. 73:1185-1190.

14. Wright, K. S., H. Beck-Nielsen, O. G. Kolterman, and L. J. Mandarino. 1988. Decreased activation of skeletal muscle glycogen synthase by mixed-meal ingestion in NIDDM. Diabetes. 37:436-440.

15. Kruszynska, Y. T., G. Petranyi, and K. G. M. M. Alberti. 1988. Decreased insulin sensitivity and muscle enzyme activity in elderly subjects. Eur. J. Clin. Invest. 18:493-498.

16. Mandarino, L. J., Z. Madar, O. G. Kolterman, J. M. Bell, and J. M. Olefsky. 1986. Adipocyte glycogen synthase and pyruvate dehydrogenase in obese and type Il diabetic subjects. Am. J. Physiol. 251:E489-E496.

17. Thorburn, A. W., B. Gumbiner, F. Bulacan, P. Wallace, and R. R. Henry. 1990. Intracellular glucose oxidation and glycogen synthase activity are reduced in non-insulin-dependent (Type II) diabetes independent of impaired glucose uptake. J. Clin. Invest. 85:522-529.

18. National Diabetes Data Group. 1979. Classification and diagnosis of diabetes mellitus and other categories of glucose intolerance. Diabetes. 28:10391057.

19. Goldman, R. F., and E. R. Buskirk. 1961. A method for underwater weighing and the determination of body density. In Techniques for Measuring Body Composition. J. Brozek and A. Dershel, editors. National Research Council, National Academy of Sciences, Washington, DC. 78-89.

20. Thorburn, A. W., B. Gumbiner, G. Brechtel, and R. R. Henry. 1990 Effect of hyperglycemia and hyperinsulinemia on intracellular glucose and fat metabolism in healthy subjects. Diabetes. 39:22-30.

21. Henry, R. R., B. Gumbiner, T. Flynn, and A. W. Thorburn. 1990. The metabolic fate of intracellular glucose in non-insulin dependent diabetes mellitus: effects of hyperinsulinemia and hyperglycemia. Diabetes. 39:149-156. 
22. DeFronzo, R. A., J. D. Tobin, and R. Andres. 1979. Glucose clamp technique: a method for quantifying insulin secretion and resistance. Am. J. Physiol. 273:E214-E223.

23. Steele, R. 1959. Influence of glucose loading and injected insulin on hepatic glucose output. Ann. NY Acad. Sci. 82:420-430.

24. Chiasson, J. L., J. E. Liljenquist, W. W. Lacy, A. S. Jennings, and A. D. Cherrington. 1977. Gluconeogenesis: methodological approaches in vivo. Fed. Proc. 36:229-235.

25. Yki-Järvinen, H., D. Mott, A. A. Young K. Stone, and C. Bogardus. 1987. Regulation of glycogen synthase and phosphorylase activities by glucose and insulin in human skeletal muscle. J. Clin. Invest. 80:95-100.

26. Bergstrom, J. 1962. Muscle electrolytes in man. Scand. J. Clin. Lab. Invest. 14(Suppl. 68):7-101.

27. Nuttall, F. Q., J. Barbosa, and M. C. Gannon. 1974. The glycogen synthase system in skeletal muscle of normal humans and patients with myotonic dystrophy: effect of glucose and insulin administration. Metab. Clin. Exp. 23:561-568.

28. Thomas, J. A., K. K. Schlender, and J. Larner. 1968. A rapid filter paper assay for UDP glucose-glycogen glucosyltransferase, including an improved biosynthesis of UDP- ${ }^{14} \mathrm{C}$-glucose. Anal. Biochem. 25:486-499.

29. Mandarino, L. J., K. S. Wright, L. S. Verity, J. Nichols, J. M. Bell, O. G. Kolterman, and H. Beck-Nielsen. 1987. Effects of insulin infusion on human skeletal muscle pyruvate dehydrogenase, phosphofructokinase, and glycogen synthase. J. Clin. Invest. 80:655-663.
30. Lowry, O. H., N. J. Rosebrough, A. L. Farr, and R. J. Randall. 1951. Protein measurement with the Folin phenol reagent. J. Biol. Chem. 193:265-275.

31. Keppler, D., and K. Decker. 1974. Glycogen determination with amyloglucosidase. In Methods of Enzymatic Analysis. H. U. Bergmeyer, editor. Academic Press, New York. 1127-1131.

32. Desbuquois, B., and J. A. Aurbach. 1971. Use of polyethylene glycol to separate free and antibody bound peptide hormones in radioimmunoassay. $J$. Clin. Endocrinol. \& Metab. 33:732-738.

33. Lawrence, J. C., and J. Larner. 1978. Activation of glycogen synthase in rat adipocytes by insulin and glucose involves increased glucose transport and phosphorylation. J. Biol. Chem. 253:2104-2113.

34. Larner, J. 1988. Banting Lecture 1987. Insulin signaling mechanisms. Lessons from the old testament of glycogen metabolism and the new testament of molecular biology. Diabetes. 37:262-275.

35. Roach, P. J., and J. Larner. 1976. Rabbit skeletal muscle glycogen synthase. II. Enzyme phosphorylation state and effector concentrations as interacting control parameters. J. Biol. Chem. 251:1920-1925.

36. Chiasson, J-L., M. R. Dietz, H. Shikama, M. Wootten, and J. H. Exton. 1980. Insulin regulation of skeletal muscle glycogen metabolism. Am. J. Physiol. 239:E69-E74.

37. Larner, J., and C. Villar-Palasi. 1971. Glycogen synthase and its control. Curr. Top. Cell. Regul. 3:195-236.

38. Bak, J. F., O. Schmitz, N. Schwartz Sorensen, and O. Pedersen. 1989. Post-receptor effects of sulfonylurea on skeletal muscle glycogen synthase activity in Type II diabetic patients. Diabetes. 38:1343-1350. 